\title{
O cultivo da mandioca por um povo indígena adventista na Amazônia
}

Caio Monticelli

Doutorando no Programa de Pós-Graduação em Antropologia Social da Universidade Federal de São Carlos (PPGAS/UFSCar).

E-mail: caio.monticelli@gmail.com

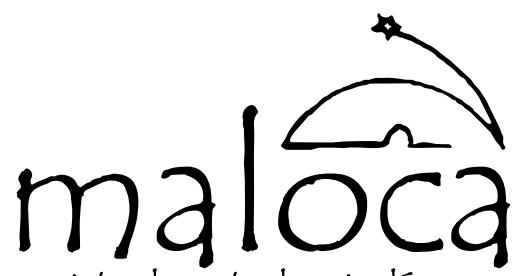

revista de estudos indígenas 


\section{Resumo}

O objetivo deste trabalho é apresentar a maneira pela qual os Taurepáng, povo indígena que vive no norte do estado de Roraima, cultivam a mandioca. De modo complementar, busca-se analisar como a prática ritual da religião adventista por parte dos moradores do Bananal, a maior comunidade taurepáng no Brasil, se relaciona com essa atividade. Ao longo do cultivo da mandioca, os Taurepáng precisam estar atentos a uma série de cuidados para com a planta, pois, capaz de retribuir afetos e desafetos, ela se vinga das pessoas que a desrespeitam. Porém, em vez de recorrerem ao possível espírito dono da mandioca para obter sucesso na plantação, os Taurepáng do Bananal optam por uma alternativa inerente à sua escolha religiosa: reivindicar Jesus Cristo enquanto entidade superior aos donos das espécies animais e vegetais que povoam o cosmos.

\section{Abstract}

The objective of this work is to present a way in which the Taurepáng, an indigenous people who live in the north of the state of Roraima, grow manioc. At the same time, it seeks to analyze how the ritual practice of Adventist religion by the residents of Bananal, the largest Taurepáng community in Brazil, is related to this activity. Throughout the cultivation of manioc, the Taurepáng must be attentive to a series of care for the plant, which, capable of returning affection and disaffection, takes revenge on the people who disrespect it. However, instead of resorting to the possible spirit that owns manioc to succeed in planting, the Bananal Taurepáng opt for an alternative inherent to their religious choice: claiming Jesus Christ as a superior entity to the owners of the animal and plant species that populate the cosmos.
Palavras-chave:

Roraima; Taurepáng; Cristianismo indígena; mandioca; donos.

Keywords: Roraima; Taurepáng; Indigenous Christianity; manioc; owners. 


\section{Introdução}

$\mathrm{N}$ o norte do estado de Roraima, em uma região de floresta tropical limítrofe com a Venezuela, vivem os Taurepáng, povo indígena que soma pouco mais de 800 pessoas $^{1}$. Suas comunidades estão distribuídas sobretudo pela parte setentrional da Terra Indígena São Marcos (TISM), de forma que a comunidade do Bananal, com cerca 450 moradores, ergue-se como o principal núcleo taurepáng no Brasil.

Quando conversam entre si, entretanto, os Taurepáng se dizem Pemon, termo que significa "gente", "pessoa", autodenominação pela qual os indígenas que vivem nas terras a oeste e sudoeste do Monte Roraima se reconhecem. A literatura compreende os Pemon como um "grande grupo étnico" subdividido entre os Kamarokoto e Arekuna, habitantes por excelência da savana venezuelana, e os Taurepáng e Macuxi, que vivem, em relação aos seus parentes na savana, mais ao sul, na faixa de fronteira entre a Venezuela e o Brasil (Thomas, 1982; Santilli, 2000). Além disso, os Pemon são muito semelhantes socioculturalmente aos Kapon, seus vizinhos que vivem nas montanhas a norte e leste do Monte Roraima. O etônimo Kapon significa "gente do alto", "gente do céu", e sua subdivisão interna ocorre entre os Patamona e os Ingarikó, também conhecidos por Akawaio (Amaral, 2019).

Apesar de mobilizarem diferenças dialetais como mecanismo de distinção social e geográfica entre seus diversos subgrupos, Pemon e Kapon conformam os dois maiores coletivos indígenas falantes de língua Carib que vivem na região guianense (Rivière, 1984). Seu território tradicional abrange as terras adjacentes ao Monte Roraima, tendo sido sobreposto, aliás, pelas fronteiras internacionais entre o Brasil, a Venezuela e a Guiana, que estabeleceram o Monte Roraima como a tríplice fronteira entre seus limites.

Distante doze quilômetros da fronteira venezuelana, a comunidade do Bananal fica a vinte e cinco quilômetros de Pacaraima, cidade localizada no interior da Terra Indígena São $\mathrm{Marcos}^{2}$. A fundação do Bananal remete aos anos 1960 e está atrelada à retomada de um antigo sítio onde, no passado, o finado Bento Loyola viveu a juventude junto ao sogro, antes de o abandonarem em decorrência de uma severa epidemia de sarampo no local. Em vida, Bento gozou de grande prestígio em meio ao seu povo, uma vez que o xamã Akuri, seu pai, guiou parte da viagem do naturalista alemão Theodor Koch-
1. https://pib.

socioambiental.org/pt/

Povo:Taurepang (acesso em: 18/01/2021).

2. Em meados dos anos 1990, o governo de Roraima transformou a então pacata vila de Pacaraima em município, estimulando a expansão de sua infraestrutura com a abertura da BR-174, conectando-a a capital Boa Vista, e atraindo novos moradores através da distribuição de lotes urbanos (ver Andrello, 2010). Nos dias de hoje, a população de Pacaraima permanece sendo majoritariamente não-indígena. Por estar localizada dentro da TI, sua situação jurídico-administrativa é controversa,

especialmente face

à intensificação da imigração venezuelana para o Brasil nos últimos anos. Em 2018, por exemplo, Pacaraima foi a cidade que mais cresceu no país; se mantiver esse ritmo, as previsões são para que dobre de tamanho em menos de cinco anos. <https:// www1.folha.uol.com. br/cotidiano/2019/08/ com-crise-venezuelanapacaraima-e-cidade-quemais-cresce-veja-outrascuriosidades.shtml> (acesso em: 03/08/21).3. Após o ritual, as esteiras são enterradas no mato ou jogadas no oco de uma árvore grande, como se faz com a placenta e o cordão umbilical do recémnascido. A saída da moça é um "renascimento", em vários sentidos (Bonilla, 2005b; 2007). 
Grünberg pela região do Monte Roraima, no início do século XX (Koch-Grünberg, 2006). Após um período de residência em Maurak, grande comunidade taurepáng situada na savana venezuelana, Bento e sua família - isto é, esposa, filhos solteiros, filhas casadas e genros se transferiram do lado de lá da fronteira para o igarapé Macaiapáng, afluente da margem esquerda do rio Surumu, no norte de Roraima. Naquela região de floresta fundaram a comunidade do Bananal, um lugar, assim como Maurak, para se viver entre parentes e praticar a religião adventista do Sétimo Dia (Andrello, 1993).

Não é exagero afirmar que a agenda interna da comunidade do Bananal intercala suas atividades basicamente entre o trabalho na roça e os compromissos religiosos. Quando seus moradores não estão ocupados em cultivar, colher ou moer mandioca nos barracões de farinha, estão reunidos na igreja para ouvir a mensagem dos pregadores, rezar e louvar em seu próprio idioma. Praticantes assíduos da doutrina adventista, eles jamais trabalham na roça aos sábados ou saem da comunidade nesse dia, reservado exclusivamente para um longo culto que ocorre em período quase integral. Outros cultos são realizados também nas noites de domingo, quarta e sexta-feira, sendo qualquer ausência prontamente percebida pelos mais velhos.

O objetivo deste trabalho, portanto, é explorar de que forma os Taurepáng do Bananal, todos adventistas, se dedicam ao trabalho na roça, com ênfase no cultivo da mandioca, sua principal fonte de alimentação e de renda. Após uma breve exposição de seu contato com a mensagem adventista e adesão da religião do Sétimo Dia, a análise volta-se para o labor na roça propriamente dito. Nele, os Taurepáng se sujeitam à interação com uma diversidade de seres espirituais que fazem das serras e floresta, rios e cachoeiras a sua morada. A argumentação que se propõe é que os moradores do Bananal compreendem que cantar a Jesus Cristo é imprescindível para o bom resultado da colheita, visto que avaliam o poder dessa entidade como superior ao dos demais donos das espécies animais e vegetais que habitam o cosmos. Contudo, mesmo invocando a Jesus Cristo, a mandioca permanece a demandar determinadas práticas específicas de cuidado. Capaz de retribuir afetos e desafetos, ela é responsável por causar quebrante, uma complexa enfermidade que se manifesta no corpo das pessoas que a desrespeitam. 


\section{Breve panorama da adesão dos Taurepáng à religião adventista}

Nas últimas décadas, é possível dizer que a antropologia aflorou seu interesse pelo modo como os povos indígenas interpretam, incorporam e praticam a religião cristã em suas diversas vertentes (Wright, 1999, 2004). Recentemente, tal campo de estudos passou a ser denominado de Antropologia do Cristianismo (Robbins, 2003, 2011), com trabalhos que buscam detalhar como as especificidades socioculturais e conceitos cosmológicos de diferentes povos entendem e dão sentido à experiência cristã (Villaça \& Wright, 2009; Robbins, Schieffelin \& Villaça, 2014).

Contudo, apesar dos avanços na área, ainda é pouco o que se tem falado do contato de um povo indígena com a religião adventista, doutrina que, de modo sui generis, estabelece uma série de restrições alimentares, a reserva do sábado como dia de adoração ao Senhor e dá grande ênfase à noção da segunda vinda de Jesus Cristo à Terra (Rocha, 1972; Oliveira Filho, 1972). Nesse sentido, os trabalhos de Andrello (1993, 1999) são em um só tempo pioneiros e exceção. Balizados por este material para em seguida avançarmos para a questão do cultivo da mandioca, veremos com maiores detalhes o particular processo de adesão dos Taurepáng à religião do Sétimo Dia.

Os primeiros contatos que tiveram com a mensagem adventista ocorreram no início do século XX, quando o missionário O. E. Davis partiu de Georgetown, na costa guianense, e, por meio de rotas fluviais através do interior da então colônia inglesa, alcançou antigas aldeias taurepáng situadas na base do Monte Roraima. À época, os missionários adventistas eram motivados pela ideia de que os povos indígenas da América do Sul estavam "pedindo ansiosamente" pelas missões, pois eram "carentes de civilização" (Prestes Filho, 2006). Todavia, quando Davis chegou nas aldeias taurepáng em 1911, encontrou índios praticantes do Aleluia, um movimento religioso de caráter profético que naquele momento estava em pleno processo de disseminação entre os Pemon e Kapon.

Estima-se que o Aleluia tenha surgido no final do século XIX, entre as décadas 1870 e 1880, quando Bichiwung, um Macuxi recém batizado, foi levado por missionários anglicanos instalados no interior da Guiana Inglesa para um lugar distante de sua aldeia e próximo ao mar, não se sabe se Georgetown ou a Inglaterra. Ao longo da estadia 
em meio aos brancos, Bichiwung se recolheu para um de seus momentos solitários de oração, quando experimentou algo semelhante ao que acontece nos transes xamânicos: durante a oração, sua alma deixou o corpo e "voou pelo céu", onde haveria se encontrado com o Deus de que tanto falavam os missionários (Abreu, 1995).

No decorrer do transe, Bichiwung fora informado pela divindade que os brancos estavam ensinando o conhecimento religioso de maneira propositalmente incorreta para os índios, pois não queriam, afinal, que eles ascendessem ao paraíso no céu que pregavam. Para contornar o ardil e alcançar tal patamar póstumo de existência, isento de doenças e mortes, a prática dos cantos e danças do Aleluia, recebidos por Bichiwung diretamente da divindade, seria a alternativa. Seu retorno para as montanhas Kanuku, no interior da Guiana, marcou o início de um rápido processo de disseminação da mensagem do Aleluia pela área circum-Roraima. Aos poucos, enquanto suas danças e cantos recebiam cada vez mais adeptos, novos profetas foram surgindo, pessoas que, tal como Bichiwung, também alegavam experimentar encontros xamânicos no céu com Deus. Posteriormente, a capacidade de reunir pessoas em torno de si estava diretamente relacionada à validade e conteúdo da mensagem que anunciavam (Amaral, 2019: 120).

Muitos desses xamãs-profetas, como ficaram conhecidos na literatura, utilizavam de palavras escritas em papel como meio específico para entrar em transe. Assim, mesmo que iletrados, "liam" antigas folhas de jornais deixadas por expedições científicas inglesas que, nas últimas décadas do século XIX, passaram a explorar o Monte Roraima em busca de espécimes botânicas raras. Esses papéis teriam sido apropriados pelos xamãs enquanto "repositório de palavras", às quais eram atribuídas, e ao ato de pronunciá-las, um poder imanente (Andrello, 1993: 113). A palavra escrita nos papéis fora manipulada, portanto, como veículo que auxilia a comunicação entre humanos e não humanos, enfatizando a busca pelo contato com a divindade trazida pelos missionários (Amaral, 2019: 115).

De fato, as terras adjacentes ao Monte Roraima foram palco para o surgimento de diversos outros movimentos proféticos ao longo do século XX - como o Chimiting (Butt, 1960; Andrello, 1993: 143), o Chochimuh (Thomas, 1982: 147; Amaral, 2019: 165) e o San Miguel (Levy, 2003) -, mas o precursor Aleluia foi o que encontrou maior 
disseminação na região. Seu impacto local foi tamanho que, em 1977, adquiriu o reconhecimento de religião oficialmente praticada na Guiana (Amaral, 2019: anexo II).

Deste modo, vemos que os primeiros contatos dos Taurepáng com a mensagem adventista trazida por Davis em 1911 ocorreram em um momento em que eles já praticavam, a seu modo, as danças e cantos do Aleluia, mostrando-se bastante familiarizados com o ideário profético de um paraíso no céu a ser vivido após a morte. Não há indícios, a princípio, de que o novo conhecimento transmitido por Davis tenha entrado em conflito com a prática taurepáng do Aleluia. Ambos parecem ter coexistido na curta estadia do missionário no Monte Roraima, vítima de uma misteriosa doença apenas quatro meses após sua chegada. Catorze anos se passaram para que os Taurepáng voltassem a ter contato com outro missionário adventista.

Se Davis ficou poucos meses entre os índios, a partir de 1925 o reverendo A. W. Cott e sua esposa empreenderam cerca de seis anos de trabalho missionário em Akurimã, a oeste do Monte Roraima, onde fundaram igrejas, proibiram o uso de tabaco e bebidas alcoólicas, condenaram o consumo de animais tradicionalmente utilizados na alimentação (como anta, paca, cotia e queixada, classificados como "impuros" ou "imundos" pela doutrina adventista), as curas xamanísticas e, evidentemente, a prática do Aleluia. Para facilitar o aprendizado da mensagem que traziam, o casal Cott iniciou a alfabetização dos Taurepáng em língua inglesa, mas, ao tomar conhecimento da situação, o governo venezuelano interpretou a presença dos missionários como um projeto colonial inglês para aquela região de fronteiras sob disputa. Assim, em 1931, A. W. Cott e sua esposa foram expulsos por militares venezuelanos e obrigados a se transferirem para o lado guianense da fronteira, onde fundaram uma nova missão (Andrello, 1993: 120).

Com a expulsão do reverendo nos anos 1930, a catequese dos Pemon na savana venezuelana ficou a cargo de franciscanos, porém, os grupos taurepáng que estiveram próximos a Cott optaram por se manterem distantes dos padres. Dando as costas para as tentativas frustradas dos católicos de convertê-los (ou melhor, desconvertê-los para depois reconvertê-los), fundaram, mais ao sul do Monte Roraima, a comunidade de Maurak. A partir desse momento, os Taurepág de Maurak passaram a viajar longas distâncias até a missão de Cott, na Guiana, para receberem ensinamentos e o batismo. Vale destacar que 
entre os primeiros moradores de Maurak encontrava-se Bento Loyola, que décadas depois, nos anos 1960, se mudou com a família para o alto curso do rio Surumu, no lado brasileiro da fronteira, onde fundou a comunidade do Bananal. A presença de missionários adventistas na Venezuela só foi readmitida em meados da década de 1950, quando uma nova Constituição assegurou a liberdade religiosa naquele país. Nesse sentido, a atual ortodoxia que se observa nos cultos taurepáng e sua rotina regular durante a semana vieram a ser paulatinamente adotados após esse período, quando novos missionários se estabeleceram em Maurak e ali construíram, nos anos 1960, um colégio adventista (Andrello, 1993: 148).

Ao contrário do que ocorreu com Davis, a convivência mais intensa dos Taurepáng com o casal Cott, entre os anos 1925 e 1931, os levou ao abandono das danças e cantos do Aleluia e à incorporação do conjunto de práticas da religião adventista. A fundação do Bananal insere-se nesse contexto, onde a intenção de Bento foi a de estabelecer uma comunidade para, assim como Maurak, viver-se entre parentes praticantes da religião adventista. Para Andrello, o abandono do Aleluia pelos Taurepáng em prol do adventismo não teria sido consequência de "mera imposição catequética". Isso porque, de acordo com o autor, "parece que do ponto de vista taurepáng, o Aleluia transmitido pelos vizinhos Akawaio e Macuxi e o adventismo trazido pelos missionários tratavam do mesmo objeto, falavam do mesmo lugar" (Andrello, 1993: 146).

Trata-se, com efeito, da perspectiva de acesso a um lugar no céu a ser vivido após a morte, caracterizado sobretudo pela ausência de fome, doenças e mortes. Tanto o Aleluia quanto o adventismo anunciam sua conquista póstuma mediante o cumprimento de uma série de práticas especificas em vida. Embora sejam diferentes, ambas religiões valorizam a participação nos cultos, encontros cerimoniais nos quais os fiéis se reúnem para ouvir as palavras de Deus transmitidas pelos pregadores, chamados de ekamanin pelos Taurepáng adventistas e de pukenak pelos Akawaio adeptos do Aleluia.

O contato prévio dos Taurepáng com o Aleluia, portanto, teria viabilizado a inteligibilidade da mensagem trazida pelos missionários adventistas, com especial ênfase na noção do iminente retorno de Jesus Cristo à Terra e de um paraíso no céu a ser vivido após a morte. Paulatinamente, diversos grupos taurepáng abdicaram das danças e cantos 
do Aleluia para aderirem exclusivamente ao conjunto de práticas da religião do Sétimo Dia. Após o batismo em massa dos Taurepáng, novos hábitos sociais e alimentares foram incorporados, como o resguardo do sábado, a recusa em consumir tabaco, bebidas alcoólicas e os animais "imundos". Isso os levou a adotar de uma dieta quase vegetariana, estruturada à base de frutas, peixe ou carne de frango e mandioca, da qual fazem a farinha e o beiju, componentes imprescindíveis de suas refeições.

\section{A roça}

Dado o objetivo do presente trabalho, uma discussão mais extensa a respeito das particularidades do adventismo praticado pelos Taurepáng e seu contraste com o Aleluia entre os Akawaio não se mostra pertinente. Mas o percurso desenvolvido até o momento nos conduz ao ponto que aqui interessa. Em linhas gerais, quando os moradores do Bananal não estão comprometidos com as atividades da igreja, estão atarefados com o labor da roça, seja plantando, cultivando, colhendo ou nos barracões da farinha. Não à toa eles se afirmam mua puekenan, o que traduzo por "agricultores", visto que o termo mua expressa uma faixa de terra destinada ao cultivo, sobretudo de mandioca, e puekenan, plural de pueken, significa "ocupado em", "entregue a", "que gosta de" (Armellada \& Salazar, 1981).

Os Taurepáng do Bananal trabalham na roça todos os dias da semana, com exceção do sábado, por motivos religiosos, e das manhãs de sexta-feira, porque comercializam seus produtos agrícolas em Pacaraima. Como viajam para a cidade toda sexta-feira de manhã, fretam mensalmente um ônibus para levá-los, mas o fretado não dá conta de transportar todas as famílias e produtos. Assim, eles também organizam um dinâmico sistema de caronas com os poucos moradores da comunidade que possuem carro, que não chega a dez pessoas. Parentes de comunidades próximas são acionados igualmente nesse dia.

Nas manhãs de sexta-feira o planejamento é chegar bem cedinho em Pacaraima, por volta das $7 \mathrm{~h}$, e retornar até às $15 \mathrm{~h}$, de preferência com tudo vendido, pois a partir do meio da tarde os Taurepáng já começam a se preparar para o resguardo do sábado. Se não fosse o comércio semanal dos produtos agrícolas em Pacaraima, suspeito que a maioria dos moradores do Bananal passaria longos períodos sem ir 
à cidade. Instalada dentro da Terra Indígena e em meio ao território tradicionalmente ocupado por esse povo, os Taurepáng consideram os brancos eneton, "bichos", e com eles evitam inclusive se casarem.

Sobre a localização das roças, elas são feitas na ampla região de floresta adjacente à comunidade do Bananal, de modo que a distância entre a casa de uma pessoa e o local de sua roça varia de acordo com o tempo em que ela reside na comunidade. Os patámoná, isto é, os "moradores antigos"3, têm acesso privilegiado às áreas mais próximas, enquanto os parentes recém-chegados da Venezuela a partir de 2018, por exemplo, em decorrência do agravamento da crise naquele país (cf. Montcelli, 2020a), ficam com áreas afastadas. Para acessá-las é necessário caminhar longas distâncias mata adentro.

O local onde os Taurepáng plantam mandioca é utilizado, em média, por até três anos consecutivos, sendo deixado outros dez para "descansar". Eles consideram que a terra precisa se recuperar do período em que a mandioca foi cultivada, caso contrário a próxima colheita será prejudicada, razão pela qual dificilmente desrespeitam o tempo de descanso do solo. Além disso, em sua concepção há uma clara distinção entre roça e sítio. Sítio é onde cultivam árvores frutíferas como cupuaçu, ingá, jambo, manga, laranja, acerola e uma variedade de bananas, já na roça plantam exclusivamente mandioca. Não há, portanto, necessidade do descanso da terra do sítio, apenas a da roça. Com a plantação de mandioca os Taurepáng fazem beiju e as farinhas do tipo branca e amarela, componentes diários de suas refeições e produtos cujo comércio em Pacaraima garante a parte substancial da renda de uma família nuclear.

A única roça coletiva no Bananal é a da escola, da qual provém a merenda dos alunos da Escola Estadual Indígena Tuxáua Bento Louredo, uma homenagem ao finado fundador da comunidade. Há um regime de rotação dos adultos que nela trabalham por semana. No mais, cada família possui sua própria roça.

Diferente do que se verifica em outras sociedades indígenas na Amazônia, como entre os Kawaiwete-kaiabi, em que as mulheres são as responsáveis por excelência pelo cultivo da roça (Zaramella, 2020), entre os Taurepáng não há uma divisão exata de trabalho entre homens e mulheres, apenas no momento do preparo do beiju, feito exclusivamente por mulheres. De modo paralelo, é frequente na comunidade do Bananal que as crianças ajudem seus pais na lavoura, acostumadas
3. Patá, em primeira acepção, significa "lugar", mas dependendo do sentido também pode expressar a ideia de "mundo". Moná, por sua vez, é "morador antigo". 
desde pequenas a percorrerem os caminhos pela mata e a identificarem rios, plantas e animais. Mas sua prioridade é a escola e dificilmente elas interrompem o horário de estudo para isso. Os mais velhos, por sua vez, cultivam a terra mesmo quando limitados pela idade e disposição física. Enquanto conseguir andar e se virar sozinho, um idoso irá cuidar da manutenção de sua roça.

Dado o padrão uxorilocal de residência pós-matrimonial amplamente difundido nas Guianas (Rivière, 1984), quanto mais filhas um homem possuir, mais genros conseguirá arregimentar para si, força de trabalho que mobiliza para a expansão da roça familiar. Mesmo que a relação de subordinação de um genro para com o sogro atenue com o paulatino crescimento dos filhos do casal (os netos do pai da espoa), ela jamais deixa de existir enquanto o sogro de um homem ainda for vivo. Não obstante, os filhos que ainda não se casaram trabalham integralmente na roça de seus pais.

A uxorilocalidade, assim, favorece o fortalecimento do laço familiar feminino em relação aos laços masculinos. A tendência, nesse caso, é que as mulheres passem praticamente a vida inteira na mesma comunidade em que nasceram e cresceram, cercadas pela mãe, irmãs, primas e avó (Belaunde, 2005). Os homens, por outro lado, ao casarem, geralmente se transferem para o local de residência do pai de sua esposa, e só depois de décadas, quando os compromissos para com o sogro atenuam, é que estarão habilitados a retornarem para perto de suas irmãs, irmãos, primas e netos.

Diante desse quadro de transferencia residencial pós-matrimonial, é digno de nota que a influência de Bento Loyola foi tamanha que Lázaro e Avelino, seus únicos filhos homens, não saíram do Bananal quando se casaram. Apesar de suas esposas serem de outra comunidade (ou seja, não se tratou de um caso endogâmico), foram elas que se mudaram para morar junto ao sogro. Além disso, anos depois os próprios pais das respectivas esposas de Lázaro e Avelino também se transferiram para o Bananal. Que fatores poderiam estar envolvidos nessa situação inusitada? Só nos cabe especular, mas talvez uma possível resposta se deva ao fato de Bento ser filho do afamado xamã, que no início do século XX guiou o naturalista alemão Theodor Koch-Grünberg pela região do Monte Roraima. À época, o jovem Akuri ainda não conhecia a religião do Sétimo Dia e se destacou aos olhos de Koch-Grünberg por suas competências xamanísticas. Passado um tempo deste encontro, 
Akuri se converteu e deixou de "bater folha", como dizem os Taurepáng para se referirem às práticas dos xamãs. Ainda gozando de prestígio entre os seus, o ex xamã passou a disseminar o conteúdo da mensagem adventista pelas aldeias que visitava, o que o tornou ainda mais conhecido na região. De acordo com Avelino, seu pai, Bento, já "nasceu na religião", isto é, em contato com a mensagem adventista. Ao que tudo indica, Bento desenvolveu o talento de Akuri para elaborar sermões e o prestígio de suas pregações se estendia do Bananal para alhures, condição que pode ter influenciado a transferência anos depois das famílias das esposas de seus filhos. Ou seja, a atração que a vida no Bananal oferece não parece residir apenas na fertilidade de suas terras, mas também em algo imaterial relacionado à habilidade que certos especialistas possuem para transmitir ensinamentos religiosos e aglutinar pessoas.

A seguir listarei algumas práticas de cuidados que os Taurepáng empregam no cultivo da mandioca, chamada de kesé em sua língua. Nelas, o respeito para com a planta e o poder da palavra a ela direcionada adquirem importância central.

Em hipótese alguma os Taurepáng consideram a mandioca um simples produto agrícola. Pelo contrário, a avaliam como um ser sentimental, cujas manifestações de afeto e desafeto se expressam de múltiplas formas evidentes, seja no resultado da safra colhida ou na saúde de quem a colheu. Ao mais grave desafeto que a mandioca pode causar os Taurepáng chamam de apuimasak, que em português traduzem por "quebrante", termo que, no entanto, não circunscreve a complexidade do fenômeno em questão. Ao analisarmos a etimologia nativa, por outro lado, nos deparamos com algo que desafia a racionalidade ocidental. Examinemos, portanto, a etimologia da palavra apuimasak.

De acordo com o dicionário pemon/castelhano de Armellada \& Salazar (1981), apuima significa "enfermar con maleficio", o que, em linhas gerais, podemos traduzir por "ficar doente". O sufixo -sak, por sua vez, é equivalente, segundo os autores, ao sufixo "ado" nos verbos em espanhol ${ }^{4}$. Assim, apuimasak denotaria a condição de "adoentado com malefício". O que chama atenção, contudo, é o prefixo $a p u$, de apuima, que significa "tapar", "obstruir", "fechar", ao passo que o termo ima indica uma qualidade em grau muito elevado 5 . Como os sintomas do quebrante se manifestam apenas por meio de fortes dores no corpo da pessoa, outra possível tradução para essa moléstia seria algo como "doença que obstrui o corpo de maneira bastante intensa".
4. Como asesinar + ado, assinado; enfermarse + ado, enfermado; etc.

5. Os sufixos ima, imã, imé denotam um superlativo, como em kanaimé, feiticeiros assassinos cuja etimologia do nome é formada pelo verbo kana, "matar", acrescido de imé, "grande". São, com efeito, os "grandes matadores" (Monticelli, 2020b). 
Ainda não estou seguro das implicações dessa tradução, tampouco se tem a ver com a noção de pessoa taurepáng, na qual todo corpo vivo é habitado por uma ou mais almas. T. Koch-Grünberg (1979-1982, vol. III: 151) fala em cinco almas, enquanto D. Thomas (1982: 142) menciona "ao menos três". De toda forma, assuntos sobre apuimasak são corriqueiros entre os moradores do Bananal, mas ainda não foi possível avançar nas explicações de como essa moléstia afeta o corpo das pessoas. Certo é que ninguém, seja homem, mulher, velho, adulto, jovem ou criança, está isento de sofrer quebrante. Sua incidência, todavia, é algo que os Taurepáng lidam com certa tranquilidade, algo radicalmente diferente do que acontece nos casos de agressão por feitiçaria (tarén) ou por roubo da alma por parte dos coletivos de seres espirituais que habitam o interior das serras, as profundezas da floresta e o mundo subaquático.

Ao que tudo indica, apuimasak é o sintoma físico de uma relação inadequada entre uma pessoa e praticamente qualquer outra coisa que exista no mundo. Pode, por exemplo, ser causado caso alguém fique "deslumbrado" (adjetivo utilizado pelos Taurepáng) com a visão de uma serra, de um rio, do pôr do sol, de um pássaro em específico ou de um cachorro qualquer. Apuimasak pode ser igualmente provocado por um parente próximo ou por uma pessoa desconhecida, e até mesmo pela água dos rios e igarapés. Nessa chave de múltiplas possibilidades, a mandioca também é fonte de quebrante. Ou melhor, quem o causa é a maniva, o caule do pé da mandioca.

O quebrante causado pela maniva se manifesta através do surgimento de uma dor repentina que rapidamente se espalha pelo corpo da pessoa. Pode, assim, começar no estômago e migrar para braços e pernas, ou, como é mais frequente, surgir no braço e se estender para o tórax, cabeça e costas. Sua incidência está relacionada ao processo de colheita da mandioca, caso o caule da maniva seja cortado e arremessado de qualquer maneira no chão. Segundo os Taurepáng, a planta compreende essa ação como um desrespeito e, enfurecida, se vinga flechando o braço de quem a maltratou. Para evitar esse tipo de problema, aconselha-se sempre a colocar as manivas cortadas de forma cuidadosa no solo.

Espécie de vingança interespecífica, o tratamento para o quebrante causado pela maniva é aparentemente simples. Consiste na defumação do corpo da vítima com maruai, resina perfumada de uma 
casca de árvore que não consegui identificar, seguido de um banho com as folhas da planta. Durante o banho, deve-se esfregar as folhas da maniva em movimentos circulares nas partes do corpo da pessoa que latejam de dor. Recomenda-se, também, de uma a duas semanas sem ir à roça, para que a saúde do enfermo se recupere por completo. Não é necessário, nesses casos, o suporte do xamã, piasán em língua taurepáng, mesmo porque esses especialistas não são bem vistos pelos Taurepáng adventistas, que os acusam de "mentirosos" e de "pessoas que mexem com demônios". Assim, a neutralização do quebrante causado pela maniva pode ser efetuada por qualquer pessoa mais velha na comunidade que saiba como fazê-la. Perguntei a uma interlocutora na faixa dos 60 anos de idade se ela rezava para alguma entidade durante o tratamento do quebrante, "apenas para Jesus Cristo", foi sua resposta.

Talvez apuimasak seja a manifestação mais dolorosa de desafeto expresso pela mandioca, mas não é a única. Avaliada como "ciumenta”, os Taurepáng entendem que a mandioca se apega com facilidade à pessoa que a plantou, considerando-a sua mãe ou pai. E não se trata de um movimento unilateral, da planta para com os humanos, pois os Taurepáng também chamam as mandiocas que plantam de umü, algo como meu filho, minha cria ${ }^{6}$. De fato, o "aparentamento recíproco" entre seres humanos e plantas cultiváveis é patente entre outros povos indígenas, como os Krahô, em que as mulheres estabelecem uma relação de parentesco com as plantas de batata-doce (Morim de Lima, 2017), e os Panará, que desenvolvem um íntimo paralelo entre a concepção e criação dos filhos com o plantio e cultivo do amendoim (Ewart, 2005). Nesse sentido, os Taurepáng complementam ao seu modo uma prática verificada em outras regiões pela literatura.

Por ser "ciumenta" e "apegada", é desaconselhado que após plantar as mandiocas sua mãe ou pai fique longos períodos sem ir à roça visitá-las, pois as crias sentem saudade e, uma vez tristes, crescem pequenas. Mandiocas miúdas são, com efeito, evidência inquestionável de descaso no cultivo, o que afinal não surpreende. Como confiar em uma pessoa que não cuida de seus próprios filhos? Mas não basta apenas visitá-las na roça. Desde o início do plantio, a mandioca gosta que converse com ela, pois assim cresce alegre em direção à voz de seu cuidador.

O bom relacionamento com a mandioca também envolve o trabalho permanente de manutenção da roça, para evitar que ervas dani-
6. Em língua taurepáng, o pronome possessivo na primeira pessoa do singular é indicado pelo prefixo $u$, ao passo que mü significa esperma, filho, cria. 
nhas cresçam no local. Além disso, uma boa mãe ou pai deve elogiar o paulatino desenvolvimento de sua cria, pedindo com palavras afetuosas para que cresça grande, para alimentar muitas pessoas, pois sem comida a vida cai em sofrimento. Quanto mais conversar com a mandioca, maior será a alegria debaixo da terra, o que a faz crescer em abundância. Materialização do afeto, o tamanho da mandioca colhida é diretamente proporcional à satisfação pessoal de quem a cultivou, consciente de que fez um bom trabalho.

A manutenção da roça e a palavra falada não são, no entanto, as únicas práticas de cuidado que produzem efeito positivo na colheita da mandioca. A palavra cantada parece ser igualmente eficaz. Mas cantada a quem?

\section{O dono dos donos}

Os Taurepáng são muito zelosos com suas roças e ouvi diversas vezes que a do velho Bento era um capricho, sempre limpa e organizada. Não deixa de ser curioso que enupen, a palavra em seu idioma para zeloso, também signifique "vigilante" (Armellada \& Salazar, 1981). Estar atento ao que se faz e por onde anda é, de fato, imprescindível. As roças, como mencionado, estão localizadas na ampla região de floresta no entorno da comunidade, de forma que para acessá-las é necessário caminhar mata adentro. Porém, a floresta também é "lugar de gente", como dizem os Taurepáng, e independente da distância percorrida, se deslocar em meio a ela sempre envolve riscos em potencial ${ }^{7}$.

Embora uma diversidade de seres perigosos viva na floresta (como Ököyimü, a serpente canibal de couro colorido que faz dos brejos e cachoeiras sua casa, Piaimã, o gigante comedor de gente que grita uh-uh-uh durante suas caçadas, ou Kambicharay, um coletivo de onças ferozes que avança e devora quem encontrar pelo caminho), os moradores do Bananal não parecem se abalar com esses possíveis maus encontros e vão à roça quase todos os dias. É como se fosse improvável de acontecer a uma pessoa que mora a vida inteira no local, o que não quer dizer que seja impossível, disso os Taurepáng bem sabem. Os Amayikó, por outro lado, são os seres que meus interlocutores mais mencionaram no decorrer do trabalho de campo. Devido ao seu tamanho pequenino em relação aos humanos, Koch-Grünberg os interpretou como
7. Inúmeras são as etnografias que atestam que a floresta é a casa de uma diversidade de seres espirituais, muitos dos quais perigosos aos humanos. Não obstante, a floresta em si é igualmente dotada de vontade própria, como nos orienta o xamã yanomami Davi Kopenawa, "a floresta é inteligente, ela tem um pensamento igual ao nosso" (Kopenawa \& Albert, 2015: 497). 
"duendes" (1979-1982 vol. III: 163), mas os Amayikó, com suas unhas e cabelos compridos, são dotados de habilidades que certamente os duendes do folclore europeu desconhecem.

Os Taurepáng compreendem os Amayikó como os moradores mais antigos da floresta, anteriores aos próprios índios, razão pela qual os consideram os "donos da selva" e a floresta inteira é sua morada. Os minérios embaixo da terra são, inclusive, os "filhos" dos Amayikó, o que faz do trabalho no garimpo uma atividade bastante perigosa para os Taurepáng, afinal demanda certa negociação interespecífica (Monticelli, 2020a: 87-96).

O canto dos Amayikó é semelhante ao da ave inhambu-relógio (Crypturellus strigulosus) e apesar de falarem uma língua que os Taurepáng desconhecem, não são considerados seres propriamente maléficos, como os Mawarí, espíritos canibais que habitam o interior das serras. Os Amayikó são entendidos pelos moradores do Bananal como pessoas que vivem nas profundezas da floresta, onde dormem em redes, fazem roça e bebem caxiri. Mas são muito mais poderosos que as pessoas comuns, visto que as onças são seus animais de estimação. Caso alguém mate algum desses animais, então os Amayikó se enfurecem e perseguem o assassino até obter vingança.

Por fazer da floresta inteira sua morada, andar pela mata e ser observado pelos Amayikó é uma situação parecida a de um forasteiro que chega na aldeia: sua presença atrai muitos olhares. Embora, via de regra, os Amayikó assustem os Taurepáng, esses seres manifestam um aprazível desejo de se casar com os índios. Nesse sentido, se uma mulher estiver caminhando sozinha pela mata, seu pretendente Amayikó pode surgir na forma de um rapaz charmoso, à sua espera com um banquete farto em delícias. Se for homem, então a aparição ocorre sob a forma de uma linda moça, de olhar penetrante e perfume afrodisíaco. Seja como for, os Taurepáng evitam andar sozinhos pela floresta e quem teve um encontro físico com um Amayikó dificilmente esquece. A pessoa fica "deslumbrada" (adjetivo novamente utilizado pelos interlocutores) e não consegue tirar da cabeça a possibilidade de prazeres inimagináveis. Todavia, como no quebrante, aqui o deslumbre também traz consequências preocupantes para a saúde.

Os sintomas que evidenciam que a alma de uma pessoa está sendo roubada por Amayikó são falta de apetite, febre e eventuais convulsões. Esse foi o caso de um jovem morador do Bananal que se apai- 
xonou por uma Amayikó e passou a se comportar de maneira inusita$\mathrm{da}$, adversa. Por mais que fosse diariamente para o sítio onde plantava laranja e cupuaçu, poucas vezes trazia alguma fruta consigo quando retornava. Segundo contam, ficava brincando com Amayikó no meio do mato até o entardecer e, ao voltar para casa, já não queria saber da família. Só pensava na amada. Durante o dia, sonhava de olhos abertos; de noite, acordava gritando, tremendo de febre. Perdeu até mesmo o interesse de conversar com seus parentes. Tudo lhe passava batido até que certo dia, debilitado, magro e sem motivação para continuar a viver, não conseguiu mais levantar da rede e se fez morrer. Dizem que sua alma foi morar no fundo da floresta, junto com a Amayikó que a roubou.

Por temer o roubo da alma, os Taurepáng de um modo geral não têm interesse em namorarem os Amayikó. Por esse motivo, quando vão à roça, a técnica que empregam para evitar os "donos da selva" é esfregar pimenta ou alho na sola dos pés antes de entrar na mata, pois os Amayikó desgostam do cheiro. Há, entretanto, uma contrapartida curiosa no relacionamento interespecífico com esses seres. A partir da consolidação, a relação de uma pessoa com algum Amayikó, é como se houvesse o estreitamento dos laços entre os coletivos envolvidos, desencadeando um processo de familiarização entre os descendentes humanos, de um lado, e os Amayikó com quem a pessoa se relacionou, do outro.

É corrente no Bananal a informação de que quando jovem, o xamã Akuri, pai de Bento, teve uma namorada Amayikó com quem fez filho. Algum tempo depois, Bento foi orientado por seu pai para o caso de estar andando pela mata e os Amayikó começarem a cantar para lhe assustar ou chamar a atenção. Segundo Avelino, seu pai Bento alertava os Amayikó, lembrando-os de que "são todos parentes", "que pertencem à mesma família”. Até hoje Avelino emprega esse procedimento para se esquivar das tentativas dos Amayikó de lhe roubarem a alma enquanto vai à roça. "Mas tem que ser descendente de Akuri mesmo", frisa o interlocutor, "porque os Amayikó conhecem". Outro aspecto interessante dessa familiarização é que, visto que as onças são os animais de estimação dos Amayikó, eles alertam seus parentes Taurepáng se houver onça por perto enquanto caminham pela floresta. Cuidam, desse modo, para 
que não haja mortes desnecessárias de nenhum dos lados: nem entre seus animais de estimação nem entre os parentes humanos que vivem no Bananal (Monticelli, 2020a).

De acordo com Carlos Fausto, a figura do dono-mestre na Amazônia indígena corresponderia a uma categoria que designa um modo generalizado de relação, encarregada por caracterizar as interações assimétricas entre coletivos humanos, entre humanos e não-humanos e entre pessoas e coisas, sejam elas tangíveis ou intangíveis. Para o autor, a imagem do dono-mestre é a forma pela qual uma pluralidade de seres aparece para outro enquanto singularidade. É nesse sentido que os chefes na posição de dono devem ser compreendidos, visto que "controlam e protegem suas criaturas, sendo responsáveis por seu bem-estar, reprodução e mobilidade" (Fausto, 2008: 333).

Guardiões das onças e dos minérios, os Amayikó não são os únicos tipos de donos que os Taurepáng conhecem. Aqui vale menção a Rató, o pai dos peixes. Durante sua viagem para o Monte Roraima, Koch-Grünberg escreveu que nas noites que antecediam a uma pescaria, os indígenas de sua equipe, dentre eles Akuri, pediam a Rató por peixes. Em um dos chamados Rató teria respondido "bom, há peixes, pegue quantos quiser", mas não sem antes exigir algo para si, "dê-me um homem para comer, não posso dar meus filhos e netos sem receber nada em troca". Perspicazes, os pescadores então ofereceram-lhe tabaco, o que Rató aceitou de bom grado. Ao retornar para o mundo subaquático, entretanto, Rató os alertou para que não fossem atingidos pelo "olhar maligno" de seus filhos. Caso os peixes sejam deixados fora d'água para apodrecerem, eles se enfurecem e "flecham" o pescador, causando-lhe febre e fortes dores pelo corpo, em especial no abdômen, cabeça, braços e pernas (Koch-Grünberg, 1979-1982 vol. III: 158-159). Sintomas, vale notar, que se assemelham aos efeitos do quebrante no corpo de quem desrespeita a mandioca.

Nota-se, com isso, que ambos os donos em questão, isto é, os Amayikó e Rató, buscam assegurar a integridade de seus filhos (onças e minérios, de um lado, e peixes, do outro), além de precaver os Taurepáng da possível vingança que pode lhes acometer. Atuam, portanto, enquanto mediadores, responsáveis por orientar a boa relação a ser adotada entre os coletivos, evitando que haja prejuízos para ambos os lados. 
Dessa maneira, andar pela mata, fazer roça, trabalhar no garimpo ou pescar nos rios e igarapés constituem muito mais que mera atividade de subsistência para os indígenas. Em seu mundo, tudo a princípio tem ou pode ter um dono (Fausto, 2008). O que dizer então de kesé, a mandioca? Teria ela também um espírito dono? Sabemos em outros contextos etnográficos que a negligência no trato com os cultivares pode desagradar o espírito dono das plantas. Essa é uma das razões para os Kawaiwete-kaiabi irem à roça somente quando se sentem alegres, caso contrário, Kupeirup pode interpretá-los com certa hostilidade, ameaçando o resultado da plantação (Zaramella, 2020). E quanto aos Taurepáng, conversar com a mandioca e evitar o crescimento das ervas daninhas na roça seria suficiente para viabilizar a prosperidade da colheita? Há motivos para suspeitarmos que não.

Entre os anos de 2005 e 2018, o antropólogo alemão Matthias Lewys realizou sucessivas pesquisas de campo junto aos Pemon na Venezuela, sobretudo em meio aos Kamarokoto e Arekuna, mas também em algumas comunidades taurepáng mais ao sul na savana. Seu trabalho aborda temas voltados especialmente para a área da etnomusicologia (ver Lewy, 2011, 2012), sem, no entanto, a ela se restringir. Em publicação mais recente, o autor afirma a existência de cantos que favorecem o crescimento da mandioca, entoados pelos Pemon a Püreri pachi, entidade que, em sua análise, corresponde ao espírito dono dessa planta (Lewy, 2017). Tal repertório seria ainda renovado por meio dos sonhos, quando, em forma de mulher, Püreri pachi visita uma pessoa e a ela transmite novos cantos.

Em 2018, ao longo dos seis meses de pesquisa de campo que realizei na comunidade do Bananal, o principal núcleo taurepáng no Brasil, jamais ouvi menção a Püreri pachi ou a qualquer entidade considerada dono da mandioca. Não presenciei, tampouco, cantorias para a planta, embora alguns interlocutores tenham me dito que cantar para Jesus Cristo favorece a boa colheita. No início, essa informação não me chamou a atenção, uma vez que os moradores do Bananal protagonizam uma vida religiosa bastante intensa. Mas, se analisada com cuidado, ela me parece complementar um outro registro, talvez mais evidente, por assim dizer, a respeito da compreensão que os Taurepáng formulam do mundo em que vivem.

Os Amayikó, como mencionado, manifestam um desejo recorrente de roubar a alma dos Taurepáng para o fundo da floresta, mas esse 
contato é evitado pelos moradores do Bananal, conscientes das consequências para si e para seus familiares que sofrerão com a perda de um ente querido. Por essa razão, quando os Amayikó atentam contra uma pessoa, os Taurepáng afirmam orar a Jesus Cristo para intervir e neutralizar seus temores. Quando perguntei a um interlocutor o porquê de não pedir ao dono dos Amayikó, se é que há algum, para que impeça que seus filhos roubem a alma dos Taurepáng que só querem trabalhar na roça, obtive como resposta a seguinte explicação: "se você tem algum problema em Pacaraima e conhece o prefeito da cidade, irá procurar a ajuda do vereador ou vai direto até o chefe?".

Além disso, em 2018 um senhor de idade bastante avançada se mudou da Venezuela para o Bananal, onde já residiam seu genro, filhas e netos, todos também recém-chegados do lado de lá da fronteira. Seu nome é John Cliffe, Taurepáng nascido na Guiana, famoso por sua competência enquanto curador. Apesar dos moradores do Bananal se posicionarem de forma contrária às práticas dos xamãs, não fizeram objeção ao velho John, entendido mais como rezador que de fato como piasán. Pouco tempo após sua chegada, os serviços de John Cliffe passaram a ser solicitados tanto pelos moradores locais como por pessoas de outras comunidades, que começaram a visitar o Bananal em busca de suas competências. John não aceita necessariamente dinheiro como pagamento, seus clientes podem retribuir com parte da safra colhida nas roças ou com mercadorias que compram em Pacaraima, como macarrão, sal, óleo, gás de cozinha, etc. Intrigado com a situação, perguntei a uma liderança na comunidade o que ela achava da vinda daquele renomado curador, respondeu-me que não via problema, pois o velho reza "somente a Jesus Cristo" pela saúde das pessoas.

Infelizmente, não consegui desenvolver uma relação de maior confiança com John Cliffe e nem sei se algum dia o farei. O velho é receoso com brancos interessados em seu conhecimento. Entretanto, me parece consistente concluir que seja ao cantar paraJesus Cristo por uma colheita abundante em mandioca, seja para pedir que interceda frente às tentativas dos Amayikó de roubo da alma ou para que cure toda uma sorte de doenças, os Taurepang do Bananal fazem um único e mesmo movimento: afirmar Jesus Cristo enquanto entidade mais poderosa que as demais que existem no mundo. Seria considerado, nesse sentido, um ser superior aos tantos donos das espécies animais e vegetais. $\mathrm{Na}$ 
hierarquia cósmica dos Taurepáng adventistas, portanto, a posição que Jesus Cristo ocupa é a de mestre dos mestres, dono dos espíritos donos: um super dono, por assim dizer, que cuida de seus filhos devotos.

\section{Considerações finais}

Diferente de Matthias Lewy, que trabalhou exclusivamente com os Pemon na savana venezuelana, os grupos taurepáng com os quais realizei pesquisa de campo aderiram a prática ritual da religião adventista de maneira mais rigorosa. Os moradores do Bananal são, em sua grande maioria, descendentes de Bento Loyola, filho de Akuri, ex-xamã e notório pregador adventista dos tempos passados. Bento também foi um pregador afamado e sua transferência nos anos 1960 de Maurak, na savana venezuelana, para o alto curso do rio Surumu, em Roraima, desencadeou a fundação de uma comunidade cuja agenda é pautada fortemente pelos compromissos religiosos.

Nas primeiras décadas após a fundação do Bananal, suspeito que seus moradores ainda caçavam com alguma frequência. Nos dias de hoje, contudo, alegam que não há mais animais de caça por perto e que é preciso passar muitos dias mata adentro para retornar com um "veado magrinho". Balizados pela doutrina adventista, o veado é praticamente o único animal que os Taurepáng caçam para se alimentarem, e interpretam sua escassez na região à construção da BR-174 nos anos 1990, distante apenas onze quilômetros da comunidade, e também ao crescimento da cidade de Pacaraima dentro da Terra Indígena. Apontam, por um lado, que o tráfego e o barulho dos automóveis na estrada espantaram os animais para longe, por outro, que o aumento do desmatamento e da poluição dos rios nas áreas ao redor de Pacaraima irão ainda matar a todos, não apenas os veados. Talvez a combinação desses dois fatores tenha favorecido a difusão da agricultura no Bananal, afinal, além de alimento ritualmente permitido ela também proporciona a principal fonte de renda das famílias que lá vivem.

Os Taurepáng recém-chegados da Venezuela podem até ser menos fervorosos com a prática da religião adventista que os moradores do Bananal, mas respeitam a dinâmica comunitária e sabem que ninguém é obrigado a permanecer no local caso se sinta desconfortável. Mas, se nela decidiram se instalar, é porque há algum motivo. Pode ser por sua localização, onde os impactos da crise venezuelana são me- 
nos intensos, ou pela prática assídua de seus moradores de um conhecimento ritual específico que afirma a conquista de um lugar no céu a ser vivido após a morte, um paraíso livre de doenças e mortes. De toda forma, assim como em suas roças abundantes de mandioca, a vida no Bananal se mostra rica em algo imaterial que está para além das plantas que cultivam. Uma espécie de bem-estar generalizado permeia o cotidiano de seus moradores, alimentados repetidas vezes pelas palavras de Deus, transmitidas pelos pregadores ao longo dos cultos semanais. Dinâmica interna que o finado Bento certamente se orgulharia. 


\section{Referências}

Abreu, Stela Azevedo de. 1995. Aleluia: o banco de luz. Dissertação de Mestrado, UNICAMP, Campinas, SP, Brasil.

Amaral, Maria Virgínia Ramos. 2019. Os Ingarikó e a religião Areruya. Tese de Doutorado, UFRJ/ MN, Rio de Janeiro, RJ, Brasil.

Andrello, Geraldo. 1993. Os Taurepáng: memória e profetismo no século XX. Dissertação de Mestrado, UNICAMP, Campinas, SP, Brasil.

Andrello, Geraldo. 1999. "Profetas e pregadores: a conversão taurepáng à religião do Sétimo Dia". In: Wright, R. (Org.). Transformando os Deuses: os múltiplos sentidos da conversão entre os povos indígenas no Brasil. Campinas: Editora da Unicamp, 285-308.

Andrello, Geraldo. 2010. "Fazenda São Marcos: de Próprio Nacional a Terra Indígena”. In: Barbosa, Reinaldo Imbrozio \& Melo, Valdinar Ferreira (Org.). Roraima: homem, ambiente e ecologia. Boa Vista: FEMACT, 67-94.

Armellada, Cesáreo de \& Salazar, Mariano. 1981. Diccionario Pemon-Castellano. Caracas: Universidad Católica Andrés Bello.

Belaunde, Luisa Elvira. 2005. "Introduccion: Cruzados y paralelos". In: Belaunde, Luisa Elvira (Org.). El recuerdo de luna. Género, sangre y memoria entre los pueblos amazônicos. Lima: Fondo Editorial de la Facultad de Ciencias Sociales, 23-56.

Carneiro da Cunha, Manuela. 2009. "Cultura" e cultura: conhecimentos tradicionais e direitos intelectuais. In: Carneiro da Cunha, Manuela (Org.). Cultura com aspas e outros ensaios. São Paulo: Cosac Naify.

Colson, Audrey J. Butt. 1960. "The birth of a religion: the origins of a semi-Christian among the Akawaio". The Journal of the Royal Anthropological Institute of Great Britain and Ireland 90 (n.1): 66-106. https://www.jstor.org/stable/2844219.

Ewart, Elizabeth. 2005. "Fazendo pessoas e fazendo roças entre os Panará do Brasil Central". Revista de Antropologia 48(1). https://doi.org/10.1590/S0034-77012005000100001.

Fausto, Carlos. 2008. “Donos demais: maestria e domínio na Amazônia”. Mana 14 (2): 329-366. https://doi.org/10.1590/S0104-93132008000200003.

Koch-Grünberg, Theodor. 1979-1982. Del Roraima al Orinoco. Volumes: I, II e III. Caracas: Ediciones del Banco Central de Venezuela.

Kopenawa, Davi \& Albert, Bruce. 2015. A queda do céu: Palavras de um xamã Yanomami. São Paulo: Editora Companhia das letras.

Levy, Gabriela. 2003. Vozes Inscritas: o movimento de San Miguel entre os Pemon, Venezuela. Dissertação de Mestrado, UNICAMP, Campinas, SP, Brasil.

Lewy, Matthias. 2011. Die Rituale areruya und cho'chiman bei den Pemón (Gran Sabana, Venezuela). Tese de Doutorado, Freie Universität Berlin, Alemanha.

Lewy, Matthias. 2012. 'Different 'seeing' - similar 'hearing'. Ritual and sound among the Pemón 
(Gran Sabana/Venezuela)”. Indiana 29: 53-71. https://doi.org/10.18441/ind.v29i0.

Lewy, Matthias. 2017. “'Com o arquivo de volta ao campo’. A reinterpretação e recontextualização das gravações de Koch-Grünberg (1911) entre o povo Pemón”. Música em Contexto 11 (1): 251288. https://periodicos.unb.br/index.php/Musica/article/view/11137.

Monticelli, Caio. 2020a. Patá matá, o que dizem os Taurepáng sobre o fim do mundo. Dissertação de Mestrado, UFSCar, São Carlos, SP, Brasil.

Monticelli, Caio. 2020b. "Kanaimé, el gran asesino". Ciencias Sociales y Religión/Ciências Sociais e Religião 22: e020028. https://econtents.bc.unicamp.br/inpec/index.php/csr/article/view/13416.

De Lima, Ana Gabriela Morim. 2017. "A cultura da batata-doce: cultivo, parentesco e ritual entre os Krahô". Mana 23 (2): 455-490. https://doi.org/10.1590/1678-49442017v23n2p455.

Oliveira Filho, José Jeremias de. 1972. A obra e a mensagem: representações simbólicas e organização burocrática da Igreja Adventista do Sétimo Dia. Tese de Doutorado, USP, São Paulo, SP, Brasil.

Prestes Filho, Ubirajara de Farias. 2006. O indígena e a mensagem do segundo advento: missionários adventistas e povos indígenas na primeira metade do século XX. Tese de Doutorado, USP, São Paulo, SP, Brasil..

Rivière, Peter. 1984. Individual and Society in Guiana: a Comparative Study of Amerindian Social Organization. Cambridge: Cambridge University Press.

Robbins, Joel. 2003. "What Is a Christian? Notes Toward an Anthropology of Christianity". Religion 33 (3): 191-199. https://doi.org/10.1016/S0048-721X(03)00060-5.

Robbins, Joel. 2011. "Transcendência e Antropologia do Cristianismo: Linguagem, mudança e individualismo". Religião \& Sociedade 31 (1): 11-31. https://doi.org/10.1590/S010085872011000100002 .

Robbins, Joel; Schieffelin, Bambi \& Vilaca, Aparecida. 2014. "Evangelical Conversion and the Transformation of the Self in Amazonia and Melanesia: Christianity and the Revival of Anthropological Comparison". Comparative Studies in Society and History 56 (3): 559-590. https://doi.org/10.1017/S0010417514000255.

Rocha, Wagner Neves. 1972. O sábado e o tempo: análise de alguns aspectos simbólicos relativos à guarda do sábado na Igreja Adventista do Sétimo Dia. Dissertação de Mestrado, UFRJ/MN, Rio de Janeiro, RJ, Brasil.

Santilli, Paulo. 2000. Pemongon Patá: território Macuxi, rotas de conflito. São Paulo: Editora UNESP.

Thomas, David. 1982. Order Without Government: The Society of the Pemon Indians of Venezuela. Chicago: University of Illinois Press.

Vilaça, Aparecida \& Wright Robin. 2009. "Introduction". In: Vilaça, Aparecida \& Wright, Robin (Orgs.). Native Christians. Modes and Effects of Christianity among indigenous People of the Americas. Burlington: Ashgate Publishing Company, 1-19.

Wright, Robin (Org.). 1999. Transformando os Deuses. Os múltiplos sentidos da conversão entre os povos indígenas no Brasil. Campinas: Editora da Unicamp. 
Wright, Robin (Org.). 2004. Transformando os Deuses. Igrejas evangélicas, pentecostais e neopentecostais entre os povos indígenas no Brasil. Campinas: Editora da Unicamp.

Zaramella, Jéssica. 2020. "Aprendendo a ouvir as mulheres Kawaiwete-Kaiabi: um breve relato etnográfico". Revista Wamom 5 (1): 75-87. https://periodicos.ufam.edu.br/index.php/wamon/ article/view/7404. 